\title{
AS FINANÇAS E O ESPAÇO GEOGRÁFICO: CONTRIBUIÇÕES CENTRAIS DA GEOGRAFIA FRANCESA E DA GEOGRAFIA BRASILEIRA
}

\author{
Fabio Betioli Contel \\ Universidade de São Paulo
}

\begin{abstract}
Resumo
O presente artigo tem como objetivo resgatar, na produção geográfica francesa e brasileira, as principais obras e autores que trataram da relação da geografia com as finanças. A primeira parte do texto retoma os escritos dos principais geógrafos franceses que analisaram a organização dos bancos e das variáveis financeiras (créditos, depósitos, investimentos) naquele país, e a segunda parte identifica as contribuições mais significativas de autores brasileiros que se empenharam na investigação da espacialidade das finanças. A pesquisa permitiu identificar que, desde a publicação da obra seminal de Jean Labasse (1955), houve importantes mudanças conceituais e temáticas nos estudos geográficos das finanças, e os ganhos explicativos conseguidos nas últimas décadas autorizam afirmar que existe uma causalidade geográfica da dinâmica financeira.
\end{abstract}

Palavras-chave: geografia; finanças; sistema financeiro; bancos; região; redes.

\begin{abstract}
This article aims to recover, in French and Brazilian geographic literature, the major works and authors dealing with the geography of finance. The first part of the text resumes the writings of leading French geographers who studied the organization of banks and finance-related variables (loans, deposits, investments) in that country, while the second part maps the most significant contributions made by Brazilian authors who investigated the spatiality of finance. This analysis reveals that, since the publication of Jean Labasse's seminal work in 1955, there have been important conceptual and thematic changes in the geographic study of finance, and advancements over the past decades allow one to argue that there is a geographical causality in financial dynamics.
\end{abstract}

Key words: geography; finance; financial system; banks; region; networks.

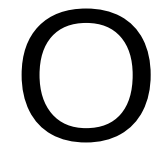

presente texto tem como objetivo resgatar, na produção geográfica francesa e brasileira, as principais obras que trataram da relação da geografia com as finanças. Para alcançar este objetivo, foi realizada uma ampla revisão bibliográfica sobre o tema, que culminou na lista de referências que segue ao final do artigo. A escolha por estas duas "escolas" de geografia para compor nosso universo social de análise se deu por três principais motivos: a. a história da geografia brasileira possui uma enorme interface com a geografia francesa, como atestam, entre outros autores, Manuel Correia de Andrade (1987) e José Borzachiello da Silva (2012); $b$. a análise dos principais textos e livros escritos sobre o tema das finanças na geografia brasileira demonstra esta relação direta com a geografia francesa; $c$. é fato notório que a obra de Jean Labasse (1955) pode ser considerada como a primeira grande sistematização, na geografia, do estudo 
das finanças. ${ }^{1}$

A primeira parte do artigo trata dos principais autores franceses que tiveram esta "dupla função": escreveram textos importantes sobre o tema das finanças, e/ou tiveram influência significativa nos debates sobre estes problemas na geografia brasileira. Cabe destacar a importância de três geógrafos principais, que cumprem estes dois papéis: Jean Labasse, Pierre Monbeig e Michel Rochefort. Na segunda parte do texto, procuramos fazer uma análise circunstanciada dos principais autores na geografia brasileira que se preocuparam em interpretar a dimensão geográfica das finanças. É possível identificar claramente duas fases nesta evolução: uma que percorreria praticamente todo o século passado (até meados da década de 1980), em que poucos textos foram produzidos sobre o tema, sendo a maior parte deles de caráter mais empírico e descritivo. Haveria uma segunda fase, que é inaugurada por Helena Kohn Cordeiro (1986/87; 1991), Roberto Lobato Correa ([1989] 2006), e Leila Dias (1989) que escreveram os primeiros trabalhos sistematicamente preocupados em entender a espacialidade das variáveis financeiras para o caso do território brasileiro.

Cabe lembrar, por fim, que o presente artigo visou dar destaque aos principais conceitos trabalhados em cada obra, no sentido de esclarecer quais os contextos epistemológicos que os autores participaram. Sejam os conceitos da área das finanças (sistema financeiro, sistema bancário, depósitos, empréstimos, etc), sejam os conceitos propriamente geográficos (gênero de vida, região/regionalismo, rede urbana, meio geográfico, etc). O texto, portanto, não pretende ser uma apresentação exaustiva de todos os títulos e autores que trataram desta relação entre a geografia e as finanças; o que se buscou, fundamentalmente, foi dar destaque às diferentes formas com que foram pesquisados estes temas, visando estabelecer um quadro verossímil de como a geografia vem explicando, a seu modo, o fenômeno financeiro. As traduções dos trechos em francês aqui trabalhados foram feitas pelo próprio autor do texto.

\section{A geografia regional francesa e as bases do estudo geográfico das finanças}

A primeira importante constatação a ser realizada, quando da consecução da revisão bibliográfica sobre o tema das finanças na geografia, é a de que a bibliografia francesa é praticamente esquecida na produção anglo-saxã, malgrado sua reconhecida importância. Ron Martin (1999), um dos principais estudiosos deste tema na Inglaterra, faz uma espécie de mea culpa sobre este problema, sob a frágil justificativa de que as principais obras francesas sobre as finanças - sobretudo as de Jean Labasse - nunca foram traduzidas para o inglês.

Na geografia francesa, é possível identificar algumas aparições do tema das "finanças" ao longo da própria evolução da disciplina, no contexto de sua sistematização efetiva com o livro se-

\footnotetext{
${ }^{1}$ Cabe mencionar ainda que, dada a grande quantidade de livros e artigos recentemente publicados por colegas anglosaxões sobre este tema, optou-se por não discutir explicitamente estas contribuições neste artigo (o que ampliaria excessivamente a proposta original do texto). Como notam geógrafos como Andrew Leyshon (1995; 1997), Ron Martin (1999), Martim Sokol (2009) e Manuel Aalbers (2015), o tema da "geografia das finanças" vem se tornando preocupação sistemática da geografia britânica e norte-americana, desde ao menos meados da década de 1990.
} 
minal de Jean Labasse (1955). Dentre as ocorrências mais significativas, estão aquelas contidas em artigos de Jean Dresch (1946; [1948] 1980). Para o autor, caberia à geografia estudar uma variável financeira essencial para o entendimento do colonialismo: os investimentos internacionais. ${ }^{2}$ Outro importante livro neste contexto é Les Marchés de Matières Premiers, de Jean Gottmann (1957). O autor mostra como se formaram os principais mercados mundiais de produtos primários, e que estes locais se tornaram também importantes praças financeiras, já que a atividade comercial internacional é uma das maiores demandadoras de dinheiro, crédito, e de todas as outras variáveis financeiras correlatas (emissão de letras de câmbio, empréstimos, comércio de moedas estrangeiras etc.). ${ }^{3}$

Um último autor francês que merece ser destacado, mas que tratou apenas tangencialmente do tema das finanças é Michel Rochefort. Em seu importante trabalho sobre a organização urbana da Alsácia, Rochefort (1960) sistematiza uma nova forma de entendimento da geografia urbana, consolidando o conceito de "rede urbana" como a principal ferramenta teórica para o estudo das regiões. Rochefort incluiu em suas preocupações aquilo que chamou de "vida de relações" das cidades, que são os conjuntos de fluxos (de pessoas, de bens, de serviços e informações) que cada aglomeração exige para seu funcionamento. O estudo da rede bancária das regiões surge justamente desta necessidade de ser bem definida a área de atuação e de polarização das cidades, a partir da definição do alcance das atividades de comércio, serviços e de administração que elas disponibilizam para seu entorno. Os bancos - junto com as demais atividades comerciais e de serviços -, o tamanho populacional e a presença de atividades industriais nas cidades, passam a ser os novos fatores para a definição dos contornos das redes urbanas regionais e, consequentemente, do funcionamento das regiões.

Neste contexto de introdução paulatina de temas financeiros na geografia francesa, podemos asseverar que dois autores tiveram papel fundamental na redação de textos diretamente preocupados em analisar esta temática: trata-se de Pierre Monbeig (1908-1987) e Jean Labasse (1918-2002).

Foi em 1957 que Monbeig faz uma apreciação sistemática do tema das finanças em artigo intitulado "Capital e Geografia". Presa ainda no paradigma da relação homem-natureza, e tendo como principais categorias o "gênero de vida" e a "paisagem", esta geografia regional francesa ainda atribuía "a chave da explicação ao clima, ao solo à estrutura geológica ou à posição geográ-

\footnotetext{
${ }^{2}$ Naquela época, o autor já se perguntava: "como compreender as transformações de nosso país, como compreender a vida humana dos países dependentes, coloniais ou neocoloniais, senão analisando as condições e as formas desta mesma dependência? Como compreender a Argélia e a Tunísia sem Rotschild, Miraben e Mallet, o Marrocos sem o Banco de Paris e dos Países Baixos, a Indochina sem o Banco da Indochina, a África Ocidental sem as sociedades de comércio, as velhas colônias sem as sociedades açucareiras, para citar apenas alguns exemplos?" (DRESCH, [1948] 1980, p. 20).

${ }^{3}$ Em seu monumental Megalopolis (GOTTMANN, 1961), o autor notou também que a ocorrência e localização do fenômeno financeiro sempre teve uma lógica geográfica própria, intimamente ligada à complexidade das atividades econômicas desenvolvidas nas cidades. Estudando o nordeste do território norte-americano, Gottmann notou que a maior parte dos montantes financeiros transacionados nos Estados Unidos passava por esta região. Isto se devia tanto à presença das sedes dos grandes bancos e instituições financeiras, assim como pela existência na região de algumas das maiores e mais dinâmicas cidades norte-americanas - sobretudo Nova Yorque, Filadélfia, Washington e Boston. Já no início do século XIX estas cidades haviam se tornado praças financeiras importantes, tanto para a economia nacional, quanto para o comércio internacional do país (GOTTMANN, 1961, p. 141).
} 
fica" (MONBEIG, 1957, p. 216). ${ }^{4}$ Para estudar a organização financeira das regiões, o autor propõe o conceito de "região bancária", que se caracterizaria da seguinte forma:

1. Os bancos, por sua "ação financeira", pelas atividades que geram e financiam, pelas relações que estabelecem e mantém com os lugares e atores financiados, "concorrem poderosamente para animar a vida regional" (MONBEIG, 1957, p. 222);

2. Apesar de não ser necessariamente visível (como os fluxos de transportes, de matérias primas, de bens e pessoas são), o dinheiro possui também uma lógica de circulação, que "ativa uma região e pode contribuir para individualizá-la" (op. cit., p. 222).

Ao se estudar esta "polarização da vida regional" a partir da ação bancária, seria possível cartografar a ação destas empresas, e contribuir para a definição precisa das regiões francesas (idem, p. 233). Nas palavras de Monbeig, "Ela (a função financeira) pouco afeta a paisagem sensível, porém constatamos a existência de uma rede de relações ligadas a alguns modos de ocupação do solo (agricultura comercializada) e, ao mesmo tempo, a gêneros de vida que trazem a marca de um longo passado. Tudo isso é geográfico, pois é cartografado com facilidade e serve para definir uma região" (MONBEIG, 1957, p. 223). Para o autor, tratar as finanças seria uma forma de definir regionalizações, mas também uma questão de definição das "funções urbanas": junto da função comercial, industrial e espiritual, a "função bancária" das cidades era um dos principais elementos que revelavam o dinamismo dos aglomerados urbanos.

O grande divisor de águas em relação ao estudo das finanças na geografia foi sem sombra de dúvida Jean Labasse, com seu impressionante Les Capitaux et la Région. Étude Géographique. Essay sur le commerce et la circulation des capitaux dans la région lyonaise (LABASSE, 1955), "uma obra magistral para a história da geografia" (BONNET, 2002). Segundo Labasse (1955, p. 513), o objetivo de seu livro seria o "exame geográfico da função financeira em suas relações com a vida regional".

A obra é escrita num período em que o sistema bancário francês passava por um significativo processo de centralização de capitais, sobretudo pelo crescimento dos bancos parisienses. ${ }^{5}$ Disto deriva a preocupação de Labasse em empreender um estudo sobre o que chamou de "regionalismo bancário", chamando a atenção para a importância de se manterem as finanças sob controle local, evitando assim a compra de bancos regionais e a hipertrofia do papel de comando da metrópole parisiense no território francês. ${ }^{6}$

\footnotetext{
${ }^{4}$ No livro que o tornou mais conhecido no Brasil - Pioneiros e Fazendeiros de São Paulo ([1952] 1984) - o autor chama a atenção para as mudanças que a expansão do cultivo do café, as migrações e a difusão das ferrovias trazem para o oeste do estado de São Paulo, dando pouco destaque aos bancos e as finanças. Para Monbeig ([1952] 1984, p. 223), "a organização do crédito fundiário" seria muito deficiente à época, e não permitia "ajuda ao simples pioneiro".

${ }^{5}$ Como mostra Jean-François Gravier em seu Paris et le Désert Français (1947), a partir do final da primeira guerra mundial foi acelerado o processo de centralização financeira no território francês, o que contribuiu para aumentar o peso de Paris no conjunto da estrutura econômica e da rede urbana do país.

${ }^{6}$ A riqueza da obra pode ser creditada tanto ao esforço de Labasse no desenvolvimento de uma abordagem inovadora para a geografia que se praticava á época, mas também por sua atividade profissional. Após se formar em geografia, em 1948 começa a trabalhar na direção de um banco de Lyon, o Banque de Neuflize (atualmente sob controle do Grupo ABN-AMRO). O fato de ter trabalhado dentro de uma instituição bancária é tido como um dos fatores explicativos da ampla e rigorosa fundamentação empírica de sua pesquisa, como nota Jacques Bonnet (2002). Obviamente, este dado biográfico do autor nos ajuda a compreender sua preocupação em manter sob controle de capitais locais os bancos regionais na França.
} 
Do ponto de vista teórico, é possível dizer que a obra de Labasse oscila entre a renovação da disciplina, e a manutenção de temas e conceitos da geografia tradicional francesa. Em seus aspectos conceituais, esta manutenção de uma abordagem tradicional é passível de ser identificada pelo uso sistemático dos conceitos de "gênero de vida" e de "paisagem", ambos se constituindo em pilares conceituais da obra. Para o autor, a ação dos bancos tem relação direta com os gêneros de vida em que atuam, sendo necessário ao banco "se integrar ao gênero de vida", "desde sua origem", para entender os "costumes locais" e "conquistar a confiança" de seu público (LABASSE, 1955, p. 241). As finanças, neste sentido, acabariam servindo como um fator que "contribui para fixar o homem na paisagem" (op. cit., p. 198). ${ }^{7}$

Paradoxalmente, ainda que a obra de Labasse guarde este caráter tradicional, ela traz também uma série de inovações do ponto de vista temático e conceitual, que merecem ser destacados. Talvez seu principal mérito seja o de ter inserido, sistemática e precocemente, o tema das finanças nos estudos geográficos. Num período em que a geografia econômica era ainda baseada em enfoques bastante empíricos, e cujas temáticas não fugiam da análise de realidades visíveis na paisagem (a agricultura, a indústria, o comércio etc.), Labasse chama a atenção para a necessidade de se entender como funcionam os pouco visíveis fluxos das finanças (sejam dos investimentos, créditos, depósitos, aplicações, das fortunas, etc.). Seu livro permite, em definitivo, que a geografia inicie um processo de recusa desta tradição empirista, fundada no paradigma da relação homem/natureza.

Labasse é um dos primeiros autores a chamar a atenção para o fato de que existe uma indissociabilidade da circulação financeira em relação à base material que a torna possível. Isto é, por mais que as finanças aparentem ser um fenômeno fundamentalmente fluido e móvel, sua circulação guarda relação estreita com as redes, infraestruturas e concentrações de fatores econômicos no espaço geográfico. Como mostra textualmente o autor, "para uma fração determinada de espaço, o estudo das relações financeiras é indissociável deste aparelho (appareil) bancário" (LABASSE, 1955, p. 4). Não são poucas as passagens também em que explicita que a extensão das redes bancárias, à época, era bastante dependente da própria rede urbana e das redes ferroviárias (já que as ferrovias eram o principal sistema de transporte até meados do século passado na Europa). ${ }^{8}$

Este raciocínio permitiu ainda que o autor propusesse uma série de considerações acerca da concentração bancária - em operação na França - e a dinâmica da rede urbana do país. Este ponto parece ser extremamente profícuo para o entendimento da dinâmica atual da rede bancária mundial. Como mostra Labasse, "A circulação de capitais se organiza num sentido único, em detrimento das províncias e em favor das metrópoles, em um movimento aparentemente irreversível" (LABASSE, 1955, p. 26). A circulação de capitais levaria à hipercefalia da rede urbana, assim,

\footnotetext{
${ }^{7}$ Para Labasse, a atividade bancária teria uma certa "atitude passiva" frente aos gêneros de vida regionais, já que, em grande parte, o banco obedece aos ritmos "naturais" das atividade econômicas (sobretudo as agrícolas, nas épocas de colheita); da mesma forma, os bancos dependem dos ritmos da produção industrial e das atividades do comércio local e regional, que acabam por ditar o maior - ou menor - dinamismo financeiro destas empresas.

${ }^{8}$ Para Labasse, "o caminho de ferro permitiu em sua origem a difusão das redes bancárias, em um sentido, as construiu" (op. cit., p. 50); e assevera ainda que haveria uma "subordinação das redes bancárias às redes ferroviárias", já que a "circulação continental prepara o caminho para a circulação de capitais e sempre o precede" (idem, p. 45).
} 
quase que necessariamente. $^{9}$

Outra importante proposta da obra de Labasse deriva de sua compreensão de que a difusão das finanças leva a um expressivo processo de racionalização do espaço e do tempo. A introdução das agências e dos guichets bancários em regiões antes não servidas por agentes financeiros - sobretudo em áreas rurais - transforma sensivelmente a realidade local, pois os produtos e serviços bancários acabam por interferir na temporalidade e na dinâmica da ação dos agentes econômicos locais. Aquele agente econômico que passa a depender do consumo de produtos financeiros (créditos, investimentos, seguros, contas-bancárias) passa a ter sua atividade comandada, em grande parte, pelas vicissitudes da instituição financeira que vende estes produtos à ele. Esta característica fica explícita quando o autor mostra que "Quanto mais os negócios são ativos, mais os homens traduzem no seu comportamento que 'tempo é dinheiro'" (LABASSE, 1955, pp. 69-70), e que os banqueiros "trabalham mais com cifras do que com homens" (op. cit., p. 272). Para Labasse, "Como todos os outros agentes de circulação, o aparato bancário contribui então para uniformizar os costumes e as mentalidades" (idem) das áreas onde se instalam. ${ }^{10}$

Por último, é importante lembrar que o livro de Jean Labasse é precursor também por ter desenvolvido um conceito que até hoje se mostraria profícuo na análise geográfica: trata-se do "regionalismo bancário". À época, o autor se perguntava: "como o exercício regional das atividades financeiras contribuiu para dar sua feição a certos agrupamentos humanos?" (LABASSE, 1955, p. 198). Para responder a esta questão, seria necessário o exame das relações entre as "estruturas bancárias e o território regional" (LABASSE, 1955, p. 198), através da identificação das características das atividades econômicas regionais, da rede de agências e guichets bancários existentes, e da dinâmica das variáveis financeiras ligadas à ação dos bancos (variações nos créditos, depósitos e investimentos, principalmente).

Uma das principais argumentações de Labasse era a de que os bancos regionais acabavam servindo para que os recursos locais fossem melhor aproveitados nas cidades e regiões em que estão instalados, já que eles possuíam uma relação muito mais orgânica com seus respectivos territórios de atuação. Para Labasse, "Os verdadeiros bancos regionais inscreveram sua rede nos limites de uma região (contrée) que eles se esforçam para desenvolver e cujo destino eles têm seu futuro ligado" (LABASSE, 1955, p. 191). Esta ligação indissociável dos bancos com seus respectivos entornos tornavam eles profundos conhecedores das "necessidades locais" (op. cit., p. 195), já que seus quadros dirigentes e o pessoal ocupado eram recrutados localmente, e os recursos drenados das atividades econômicas seriam reinvestidos local/regionalmente - "resistindo à centralização parisiense" (idem, p. 195).

\footnotetext{
${ }^{9}$ Cabe lembrar que este livro de Labasse é escrito num momento de início da renovação da geografia francesa, seja pelas propostas seminais de Pierre George - que começa a introduzir a epistemologia marxista na geografia francesa ou pelas contribuições não menos importantes de Jean Tricart sobre a geografia urbana. Data desta época o desenvolvimento do conceito de Rede urbana e de vida de relações na geografia francesa - como vimos para o caso de Michel Rochefort - que trariam ganhos explicativos significativos ao conhecimento geográfico.

${ }^{10}$ Relacionado com o tema da racionalização do espaço, o autor mostra também como os bancos são agentes da manipulação da "informação". Ainda que o termo não tenha sido tratado efetivamente como um conceito em suas propostas, Labasse chama a atenção para o fato de que, nas regiões em que atuam, os bancos são o "primeiro centro de informação em matéria econômica", já que produzem informações "diretas" e "objetivas" (LABASSE, 1955, p. 81) em suas respectivas áreas de atuação. O balcão das agências é o primeiro lugar onde comerciantes "estrangeiros" vêm procurar dados sobre a região, dada a importância desta atribuição dos bancos.
} 
A segunda grande obra de Jean Labasse sobre estes temas se intitula L'Espace Financier. Analyse geógraphique (1974), que pode ser considerado já um livro de maturidade do autor. Ali ele se propõe fundamentalmente ao "exame do desenvolvimento espacial das funções financeiras" (LABASSE, 1974, p. 9), em suas mais variadas dimensões. Assim, faz um apanhado bastante interessante sobre o que o chamou de "infra-estruturas regionais e urbanas para os movimentos de capital", e do próprio "desenvolvimento espacial das funções financeiras".

Entre outros aspectos que tornam este segundo livro de Labasse de enorme interesse para a geografia está o fato de que o fenômeno das finanças é apresentado também em sua dimensão mundial (e não mais apenas nas dimensões locais e/ou regionais, como em sua primeira obra). Labasse define o que seriam à época as "grandes praças financeiras do mundo", identificando sua importância para os movimentos de capitais na década de 1970. Para o autor, estas "grandes praças" se definiriam tanto por um "histórico" de polarização econômica, assim como pela presença de "sedes de empresas" (financeiras e não-financeiras), "bolsas de comércio" e "bolsas de valor" (LABASSE, 1974, p. 218 e ss.). Estas "cidades financeiras" que se formam - desempenhando funções financeiras importantes nos seus territórios -, comandam a divisão do trabalho da rede urbana, assim como possuem em seu espaço interno parcelas inteiras voltadas para a localização de atividades diretamente ligadas aos grandes bancos. ${ }^{11}$

Além desta dimensão urbana - seja ela internacional, ou intraurbana - Labasse segue analisando as consequências do funcionamento das instituições financeiras para aquilo que chamou de "fisionomia financeira das regiões" (LABASSE, 1974, p. 163), isto é, as características dos equipamentos financeiros de cada região, seja do ponto de vista das infraestruturas presentes, seja pela análise dos fluxos e estoques de capitais. Ao analisar estes fluxos e estoques das variáveis financeiras em cada região (principalmente os estoques de depósitos e empréstimos), Labasse propõe que existiriam "regiões fortes" e "regiões fracas", de acordo com o coeficiente entre população/depósitos/créditos. As "regiões fortes" seriam aquelas em que os créditos concedidos teriam um valor maior que os depósitos realizados, e que por sua vez, fossem proporcionalmente maiores que as populações localizadas naquela região. Por sua vez, as "regiões fracas", seriam aquelas em que os créditos concedidos seriam em menor quantidade do que os depósitos realizados, e que por sua vez seriam ainda menores do que o contingente populacional da região em questão.

\section{As contribuições da geografia brasileira ao tema das finanças}

Os estudos na geografia brasileira sobre as variáveis financeiras permaneceram bastante escassos até meados da década de 1980. Salvo raras exceções, pesquisas sobre esta temática eram na verdade "apêndices" de assuntos mais tradicionalmente tratados pela geografia econômica,

\footnotetext{
${ }^{11}$ Formam-se dentro das cidades o que o autor chamou de "localizações primárias" ligadas à atividade financeira (bairros de negócios/áreas centrais), assim como "localizações secundárias", caracterizadas principalmente pelas agências/postos e guichets instalados em bairros periféricos.
} 
como a agricultura, as cidades e suas funções, os transportes, a indústria e o comércio. ${ }^{12}$

Dentre estes estudos esparsos, cabe lembrar o artigo de Oswaldo Benjamim de Azevedo (1962), que analisou as "funções urbanas e regionais" do comércio da cidade do Rio de Janeiro, dando destaque para sua "rede bancária". Num texto bastante elegante, mas ao mesmo tempo descritivo e de viés empírico, Azevedo mostra como se desenvolveram, ao longo da história, as funções propriamente urbanas da cidade, dando detalhes das diferentes formas de comércio (varejista, atacadista, central e de bairro) e quais as principais mercadorias disponibilizadas por estas "casas comerciais". Escrito num período em que o Rio de Janeiro ainda era a principal praça financeira do território, Azevedo (1962, pp. 149-150) mostra que a capital fluminense possuía "a maior rede bancária concentrada numa só cidade, no Brasil, e esta cidade se presta a esta expansão, dada a sua extensão tanto horizontal quanto vertical, que cria concentrações maciças de consumidores e de comércio". ${ }^{13}$

Neste mesmo período, Uyvão Antonio Pegaia defende seu mestrado na Universidade de São Paulo - sob orientação de Aroldo de Azevedo - intitulado A rede bancária da cidade de São Paulo (PEGAIA, 1965). A primeira característica que chama a atenção na obra é a própria dificuldade explicitada pelo autor em relação à sua busca de textos/livros sobre o tema das finanças e dos bancos. Para Pegaia (op. cit., p. 3), "embora nos interessássemos bastante, não encontramos na bibliografia geográfica, nem mesmo na internacional, um trabalho igual ao nosso". Estas dificuldades parecem ser extremamente significativas da pouca importância do tema para a geografia da época. ${ }^{14}$

O trabalho de Pegaia faz uma descrição minuciosa e aprofundada da localização das sedes e das agências bancárias na cidade de São Paulo, dando destaque, em primeiro lugar, para a diferenciação daquelas que estão situadas na área central da cidade e as que se encontram nos bairros. Junto deste esforço, o autor recupera também a história dos bancos desde sua localização na então "Província" de São Paulo do Século XIX, até as primeiras décadas do século XX. Entre outros aspectos bastante interessantes da pesquisa está a classificação dos bancos que o autor propõe, que é bipartida: por um lado, faz uma divisão dos bancos em função de seu tamanho financeiro, encontrando em São Paulo bancos "bilionários", "milionários" e "pequenos". Concomitantemente a esta divisão, propõe que existiriam em São Paulo bancos de caráter "local", "regional" e "nacional", levando em consideração, portanto, as "diversidades de tamanho" e a "dis-

\footnotetext{
${ }^{12}$ O tema da geografia da moeda aparece em artigo de 1929, intitulado "Áreas geográficas do dinheiro", de Isaura Gasparini. De forma bastante empírica, e atrelada a uma metodologia histórica descritiva, Gasparini retoma o surgimento das primeiras civilizações no Oriente Médio e Ásia, listando as principais formas que ao longo da história as moedas tomaram.

${ }^{13}$ Apenas no final do artigo é que o autor faz uma breve descrição sobre aquilo que chamou de "rede bancária" da cidade. Notava à época que esta rede bancária do estado estaria se "expandindo fantasticamente nos últimos tempos". Azevedo (op. cit., p. 149), tendo como principais concorrentes os bancos mineiros e paulistas. Na explicação do autor, "Sugando o dinheiro arrecadado nos centros de maior movimento econômico, através de suas filiais e agências, vão esses bancos aplicá-lo onde há maior procura, seja nos centros industriais ou nas praças de exportação e de importação, seja nas zonas de produção, em que a diferença de época das safras do café, algodão, milho, feijão, arroz, etc., facilita a mobilização dos capitais de modo a aproveitar as melhores possibilidades" (idem, p.149).

14 "Do ponto de vista geográfico, não conhecemos trabalhos publicados sobre o assunto. Do ponto de vista histórico, apenas alguns estabelecimentos oficiais foram estudados. A maioria dos poucos trabalhos publicados sobre os bancos brasileiros, versa quase que exclusivamente sob os ângulos jurídico, contábil, etc. de reduzido valor geográfico. [...] A vasta bibliografia que apresentamos nas últimas páginas reflete, antes de tudo, o pouco conteúdo geográfico de que são dotados os trabalhos " (PEGAIA, 1965, p. 4).
} 
tância das áreas de influência de cada entidade" (PEGAIA, 1965, p. 110).

Há dois outros trabalhos encontrados em publicações do Conselho Nacional de Geografia/IBGE, que são representativos desta época "pioneira" de estudos sobre a relação das finanças com a geografia. Trata-se dos textos de Ceçary Amazonas - publicado na obra O Rio de Janeiro e sua região (1965) - e de Maria Rita da Silva Guimarães - publicado em A Área Central da cidade do Rio de Janeiro (1967). O primeiro livro - coordenado por Lísia Bernardes - busca a definição da "área de influência" do Rio de Janeiro, e reflete plenamente a nova metodologia de análise das redes urbanas criada por Michel Rochefort (em sua obra de 1960, já mencionada). O segundo livro, coordenado por Aloísio Capdeville Duarte, visa definir quais as principais "funções urbanas" da área central do Rio de Janeiro à época (entre elas as funções portuária, político administrativa, comercial, industrial, cultural e bancária). Em seu estudo específico sobre as funções bancárias do Rio de Janeiro, Ceçary Amazonas (1965, p. 110) mostra que,

a organização do serviço bancário corresponde, de maneira bastante aproximada, à hierarquia de centros dos centros urbanos. As cidades onde estão situadas as matrizes, filiais ou sucursais de bancos são, quase sempre, grandes centros urbanos; aquelas onde se situam as agências bancárias, correspondem a centros urbanos médios e, onde existem escritórios, encontram-se, justamente, os pequenos núcleos urbanos. Verifica-se, também, que as cidades que possuem maior número de agências bancárias são as de maior desenvolvimento, sendo este critério muito expressivo para o estabelecimento de uma hierarquia dos centros urbanos. ${ }^{15}$

Este panorama é alterado principalmente por cinco geógrafos no Brasil, que passaram a realizar pesquisas mais sistemáticas sobre a relação da geografia com as finanças. Trata-se de Helena Kohn Cordeiro, Roberto Lobato Correa, Carlos Augusto Franco da Silva, Milton Santos (junto de María Laura Silveira) e Leila Christina Dias. Entre outros fatores que permitem dizer que entramos em uma nova fase da análise das finanças pela geografia no Brasil estão:

1. o caráter nacional e internacional destes estudos, ultrapassando a preocupação mais regional - ou local - dos esforços anteriores;

2. a introdução de pressupostos da economia política (sobretudo através dos temas do "capitalismo monopolista" e da "centralização dos capitais"), conjugados às preocupações com a dinâmica rede urbana e da metropolização do comando do território;

3. a preocupação não só com o sistema bancário comercial, mas também com todos os demais atores e instituições do sistema financeiro (incluindo aí o próprio Estado e o Banco Central do Brasil, com suas leis e normatizações sobre a atividade financeira);

4. a incorporação do estudo da "base material" que permitiu a expansão das redes bancárias, principalmente as chamadas "técnicas da informação" (telecomunicações, informática, centros de processamento de dados, etc.), consolidando também a "informação" ela própria

\footnotetext{
${ }^{15}$ Outra constatação interessante do estudo é a de que a cidade do Rio de Janeiro disputava à época a influência financeira com a cidade de São Paulo, e também com Juiz de Fora (MG), onde estava sediado o Banco de Crédito Real de Minas Gerais. Porém, para além destas disputas por mercados regionais, a autora identificava também a importância nacional do Rio de Janeiro em termos de atividade bancária, já que estava então localizada na cidade a sede do Banco do Brasil (em vias de se transferir para Brasília). Por fim, a autora menciona que a "posição geográfica" do Rio de Janeiro, e as facilidades que ela permite à comunicação com outras praças financeiras do país, seria também um fator que aumentaria a influência da cidade no sistema bancário nacional, já que grande parte daqueles bancos que não possuíam sede na cidade, mantinham ali atividades de sua diretoria, para gerenciar problemas em outras áreas/cidades financeiramente dinâmicas do território (AMAZONAS, 1965, p. 111).
} 
como uma categoria central para o estudo das finanças. Um dos conceitos que talvez meIhor reflitam esta novidade é o de "meio técnico-científico-informacional", proposto por Milton Santos $(1994 ;$ 1996).

Devemos a Helena Kohn Cordeiro $(1985 / 86 ; 1991)$ estudos pioneiros sobre as finanças no Brasil. A autora, baseada também em uma bibliografia de matriz anglo-saxã, analisa o sistema financeiro a partir de sua manifestação no conjunto da rede urbana do território nacional. Cordeiro está fundamentalmente preocupada com o que chamou de "centros transacionais" ("transactional centers") da economia metropolitana, e mostra que estes centros, além de serem o lócus de tomada de decisão das grandes corporações, serviam também como relais para assegurar a interiorização gradual da economia internacional no país, dando continuidade à "relação dominaçãodependência" no contexto da divisão internacional do trabalho contemporânea.

Interessante notar ainda que as funções transacionais são diretamente identificadas com as sedes das grandes empresas. ${ }^{16}$ Dentro das grandes corporações, caberia destacar aquelas funções que fariam parte do "setor quaternário" (conceito proposto por Jean Gottmann em seu Megalopolis, de 1961), isto é, as atividades diretamente ligadas à tomada de decisões das firmas, que tem como insumo estratégico as "informações".

Ao analisar a distribuição dos pontos de controle do setor financeiro no espaço brasileiro, Cordeiro também identifica questões que viriam a ser tratadas por Corrêa ([1989] 2006), definindo ao menos quatro características principais da rede urbana em processo de transformação:

1. aumento da centralidade de São Paulo, que se torna paulatinamente o epicentro das atividades financeiras do território. Concomitantemente, ascende - em menor proporção - a centralidade de Brasília, assim como decresce a importância do Rio de Janeiro no contexto do sistema financeiro brasileiro;

2. diminuição sensível do número total de bancos comerciais no Brasil, tendo sido extintos um conjunto significativo de bancos médios e pequenos, instalados fora de cidades metropolitanas (sobretudo em cidades médias, com funções de capital regional); ${ }^{17}$

3. aumento do número e diversificação dos tipos de empresas financeiras (incluindo aí as não-bancárias), resultado da própria complexificação da divisão financeira do trabalho iniciada após a Reforma Bancária de 1964/65; dentre as instituições que aumentam de número estão as companhias de seguros, as corretoras de valores, bancos de investimento, sociedades de crédito imobiliário, entre outras;

\footnotetext{
${ }^{16}$ Para a autora, "entre as áreas de localização dos recursos produção/consumo/ poupança/desperdício, há conjunções ou pontos de controle. Localizam-se aí as grandes empresas do sistema econômico, que são proeminentes pela sua importância na organização de grande parte do sistema, trazendo também a agregação de múltiplas fontes menores. Assim os endereços de suas sedes tendem a dominar o processo de localização dos pontos de controle da geografia econômica da nação" (CORDEIRO, 1986/87, p. 156).

${ }^{17}$ Dentre as cidades que possuíam seus bancos comerciais próprios ainda no final da década de 1970, podemos destacar tanto as capitais de estado "fora" do eixo Rio-São Paulo (Maceió, São Luís, Natal, João Pessoa, Aracajú, Vitória, Manaus, Goiânia, Teresina, Campo Grande), mas também cidades de porte médio e pequeno no interior do país, como no estado de São Paulo: Ribeirão Preto, Birigui, Marília, Monte Azul Paulista, Americana, Campinas, Santos, Mococa, Cravinhos, São Joaquim da Barra, Caconde, Presidente Prudente e Jaú; no Rio de Janeiro: Niterói, Cantagalo, Campos e Teresópolis; em Minas Gerais: Juiz de Fora, Sete Lagoas, Mirai, Frutal, Uberaba, Araxá, Visconde do Rio Branco, e Betim; no Espírito Santo, Cachoeiro do Itapemirim; no Paraná, em Ponta Grossa; no Rio Grande do Sul, em Santa Cruz do Sul; no Rio Grande do Norte, em Mossoró; na Bahia, em Feira de Santana; em Pernambuco, Juazeiro; e no Piauí em Parnaíba (CORDEIRO, 1986/87).
} 
4. identificação, nas metrópoles, de áreas que se especializam por localizar fatores de atração destas empresas de controle transacional da economia (áreas que a autora iria denominar de "complexos corporativos metropolitanos" (CORDEIRO, 1993)).

Neste mesmo período, Roberto Lobato Corrêa escreveu dois principais textos sobre o tema das finanças, dando ênfase à espacialidade do sistema bancário nacional. Um deles foi escrito no ano de 1989, intitulado "Concentração bancária e os centros de gestão do território" ([1989] 2006), publicado originalmente na Revista Brasileira de Geografia (e republicado em coletânea do próprio autor). No outro, "Dinâmica do espaço financeiro brasileiro" (1993), Corrêa retoma alguns conceitos pensados em 1989 e atualiza a maior parte dos processos estudados naquela oportunidade. Neste texto de 1993, traz uma importante definição sobre a relação entre o espaço geográfico e as finanças, ligada ao que chamou de "espaço financeiro". Para o autor,

entendemos por espaço financeiro o conjunto de lugares no qual se verifica o processo de circulação de capital relativo aos depósitos, empréstimos, descontos, cobranças, juros, lucros e rendas, assim como salários, investimentos e serviços, que envolve pelo menos uma unidade do setor financeiro, até mesmo uma única agência (CORRÊA, 1993, p. 163).

Corrêa mostra nos dois textos como é possível analisar a rede urbana brasileira a partir da presença - maior ou menor - de equipamentos financeiros, destacando aí as sedes (headquarters) e as agências de bancos comerciais. Para Corrêa ([1989] 2006, pp. 61-62), "o processo de criação, apropriação e circulação do valor, fundamental, mas não exclusivo, para a organização do espaço capitalista, passa necessariamente pela atividade bancária". As cidades da rede urbana brasileira que apresentam uma maior quantidade - e complexidade - de fixos geográficos ligados às finanças podem ser consideradas como "centros de gestão do território", e é dali que partem as ordens e os fluxos de informação para as demais cidades da rede urbana nacional.

Outro aspecto extremamente importante da atividade bancária que Corrêa chama a atenção é a própria divisão territorial do trabalho dentro das corporações financeiras, que acaba por repetir a hierarquização dos centros urbanos da rede de cidades nacional: há cidades que abrigam sedes de bancos (que são fixos geográficos muito mais raros), há cidades que possuem apenas agências bancárias, e há cidades onde sequer existem equipamentos voltados para a prestação de serviços bancários (mesmos os mais simples). Para o autor, "é mediante a atividade bancária, naquilo que ela participa do processo de circulação, que também se viabilizam a divisão territorial do trabalho e a integração espacial de distintas unidades de área" (CORRÊA, [1989] 2006, p. 62).

Através do tratamento de dados estatísticos do Banco Central do Brasil (destacando os anos de 1941, 1961 e 1985), o autor também definiu que, na história do território, houve uma expressiva concentração bancária, que acabou por redundar num significativo processo de centralização de capitais, e por conseguinte, numa perda de importância econômica de cidades médias e pequenas, que tiveram seus bancos locais/regionais comprados por instituições maiores (geralmente já sediadas nas grandes metrópoles nacionais da Região Sudeste). ${ }^{18}$

Além do conceito de "gestão do território", outro par conceitual extremamente importante

\footnotetext{
${ }^{18}$ Corrêa nota também que "No bojo do processo de concentração bancária, a metrópole de São Paulo emerge como o mais importante centro de decisões financeiras do país: se em 1941 a cidade do Rio de Janeiro com suas 134 sedes de bancos era o principal centro financeiro do Brasil, em 1985 a metrópole paulista colocava-se em primeiro lugar, suplantando de muito a metrópole carioca" (CORREA, [1989] 2006, p. 65).
} 
que o autor se vale para entender a espacialidade dos bancos comerciais no Brasil é o de "dispersão/concentração". Ao mesmo tempo em que diminui o número de centros de gestão, aumenta a quantidade de fixos geográficos voltados para a prestação dos serviços financeiros (principalmente as agências bancárias). Ou como mostra Corrêa ([1989] 2006, p. 64), "esse processo de concentração/dispersão dos bancos foi acompanhado pela progressiva criação de redes nacionais de bancos comerciais, os quais são os núcleos de poderosos conglomerados financeiros".

O terceiro autor fundamental para entendermos o funcionamento dos bancos no território brasileiro é Carlos Alberto Franco da Silva (1994; 1999). Silva (1994, p. 1) mostra a importância do sistema financeiro para a sociedade capitalista atual, já que ele "permeia todo o processo de criação, apropriação e circulação do valor em várias escalas geográficas". Neste texto o autor faz um significativo resgate das principais mudanças normativas e de regulação por parte do Estado que permitiram a já mencionada concentração bancária que ocorreu no território brasileiro a partir das décadas de 1960 e 70. Identifica também a ascensão de São Paulo como principal praça financeira do território neste mesmo período, e analisa ainda o crescimento exponencial dos bancos comerciais privados nacionais à época (principalmente Bradesco, Itaú, Unibanco, Nacional e Real). Assim como a totalidade dos demais analistas do período, mostra que desde a década de 1970 diminui-se o número de bancos regionais e foi aumentado o que considerou de bancos "de atuação extra-regional", concomitantemente a um progressivo incremento do número de agências bancárias no território. Segundo o autor, "o processo de concentração-dispersão do sistema bancário determinou uma forma espacial de centralização do capital financeiro e uma hierarquização dos espaços financeiros" (SILVA, 1994, p. 20).

Em texto posterior (SILVA, 1999) estuda o processo de automação bancária de uma instituição específica, o antigo Banco Nacional S/A (atualmente incorporado ao Grupo Itaú/Unibanco). Seu estudo destaca a importância da automação bancária na década de 1990, dada pela maciça utilização da microeletrônica e da informática nos bancos comerciais, que concedeu a eles maior eficiência organizacional, flexibilidade e mobilidade dos fatores de localização, o que levou ainda a uma ampliação das unidades de captação de recursos (SILVA, 1999, p. 56). ${ }^{19}$ Por fim, destaca ainda que havia se dado uma "desmaterialização" das tarefas dentro da organização, que acabaram por mudar a forma dos fluxos dentro e entre as agências: "o apoio da telefinformática reduzia, cada vez mais, os fluxos de mão-de-obra e de documentos entre as agências e os substituía por fluxos imateriais de informações" (op. cit., p. 66). ${ }^{20}$

Contribuições significativas para o tema em tela foram realizadas por Milton Santos desde a

\footnotetext{
${ }^{19}$ Este processo de automação bancária teria sido estimulado pela própria centralização de capitais no setor, já que os grandes grupos criados geravam excedentes suficientes para o reinvestimento em inovações e tecnologias bancárias. Além desta centralização de capitais, as necessidades de se gerenciar as rápidas variações nas taxas de inflação, a internacionalização da economia e do sistema financeiro foram identificadas também pelo autor como fatores decisivos para o incremento da automação (SILVA, 1999). Para Hindenburgo Pires (1997, p. 65), houve três causas principais para que fossem iniciados os investimentos em automação bancária no Brasil: 1. As reformas administrativas no sistema bancário realizadas a partir da década de 1960 (incluindo as restrições para a instalação de agências de bancos de capital estrangeiro no território); 2. As iniciativas pioneiras de produção dos primeiros computadores brasileiros (contando com instituições universitárias como a PUC-RJ e a POLI-USP e com empresas nacionais, como a Cobra, e a Procomp); e 3. A existência de uma política de reserva de mercado para o setor de informática.

${ }^{20}$ Conforme mostra Lia Osório Machado (1996, pp. 45-46), "a expansão da rede de transmissão de dados transformou o dinheiro em 'bit de informação'. A transferência eletrônica confere um caráter volátil e anônimo ao dinheiro, constituindose, talvez, no principal fator isolado de impedimento as tentativas de regulação e de controle sobre sua origem".
} 
publicação de sua obra magistral, A Natureza do Espaço (1996). Este livro, junto da obra O Brasil: Território e sociedade no início do século XXI (escrito com a geógrafa María Laura Silveira, 2001), permitiram uma nova interpretação do fenômeno das finanças na geografia.

No livro A Natureza do Espaço, Santos nos mostra que a ação das firmas financeiras - sobretudo aquelas de alcance global - são a manifestação mais bem acabada daquilo que o autor chamou de "três unicidades" do atual período da globalização. A circulação acelerada e volumosa das finanças globais atesta que existem:

1. uma "unicidade técnica", que é permitida pela nova base material que une as diferentes regiões produtivas do globo, e é fundada principalmente pelas "técnicas da informação";

2. uma "unicidade do tempo" - ou "convergência dos momentos" - que é tornada viável por esta nova base técnica, e que leva "a possibilidade de conhecer instantaneamente eventos longínquos e, assim, a possibilidade de perceber sua simultaneidade" (SANTOS, 1996, p. 157); e por fim, mas não menos importante;

3. uma "unicidade do motor", que por sua vez é fruto deste alcance estendido das empresas globais a toda parte da superfície terrestre. Em função desta nova topologia das grandes corporações, a mais-valia por elas produzida se torna global, e acaba por se constituir no grande "motor da vida econômica e social de todo o planeta" (op. cit., p. 163).

Este conjunto de características que dá identidade à globalização fez com que duas variáveis ganhassem enorme força: as finanças e a informação (SANTOS, 1996; 2000). Dado o poder que adquiriram os atores financeiros, é possível mesmo, segundo o autor, dizer que vivemos em um período histórico baseado numa "tirania do dinheiro". Esta tirania é derivada tanto da força econômica e política das grandes corporações financeiras (bancos globais, organismos financeiros multilaterais, fundos de pensão, bolsas de valores, investidores institucionais etc.), quanto da disponibilização - seja por órgãos internacionais, seja pelas próprias normas estado-nacionais de um conjunto de leis e regulações que facilitam e dão legalidade a ação hegemônica destas corporações. É vastamente conhecido o fato de que os organismos multilaterais internacionais (como a Organização Mundial do Comércio, o Fundo Monetério Internacional e o Banco Mundial) trabalham para tornar mais veloz e onipresente a circulação do capital financeiro, e desregular os mercados nacionais dos países, para adequá-los às vicissitudes destas já citadas corporações globais. Para Santos, em função deste novo contexto,

Nunca na história do homem houve um tirano tão duro, tão implacável quanto este dinheiro global. É esse dinheiro global fluido, invisível, abstrato, mas também despótico, que tem um papel na produção atual da história, impondo caminhos às nações (SANTOS, 1999, p. 10).

Como mostra ainda o autor (SANTOS, 1996, p. 160), com a globalização se dá o "casamento" das técnicas da informação com as técnicas financeiras, permitindo que os operadores financeiros possam "funcionar todo o tempo e em todos os lugares", tendo à sua disposição um meio geográfico extremamente eficiente para a transmissão de informações e ativos financeiros (o chamado meio técnico-científico-informacional). Santos (2000) assevera ainda que este aumento do poder dos atores financeiros pode ser identificado em função de outros elementos centrais da economia contemporânea:

1. As grandes empresas possuem seus próprios setores financeiros, mesmo que a ativida- 
de-fim delas não seja financeira (firmas ligadas ao agronegócio, indústrias, empresas de comércio, serviços, etc.);

2. Em função destas novas bases técnicas e políticas, que "ofereceram novos suportes à circulação do dinheiro" (SANTOS, 1996, p. 165), ocorreu também uma ampla e profunda monetarização da vida cotidiana;

3. Acirrou-se a concentração da riqueza e dos fatores produtivos mais modernos em pontos específicos do globo terrestre, com aumento da desigualdade do poder econômico e político das nações.

Estas considerações de caráter mais teórico foram a base para que Milton Santos - junto de María Laura Silveira - fizessem uma análise pormenorizada do sistema financeiro e bancário brasileiros, no já citado livro O Brasil (SANTOS \& SILVEIRA, 2001). Para os autores, existe atualmente uma "relativa superioridade técnica e política do subsistema financeiro" (op. cit., p. 185) em relação aos demais circuitos econômicos, possibilitada principalmente por esta nova base técnica, e pela desregulação recente do setor.

Para empreender a parte empírica do livro, Santos e Silveira analisam o que chamaram de "topologia bancária", isto é, a distribuição e os diferentes tipos de fixos geográficos que constituem as principais "praças financeiras" e as redes de prestação de serviços bancários no país. Segundo os autores, com a expansão do alcance das redes bancárias - principalmente através da difusão das agências - e com a concentração do comando do sistema bancário em algumas praças financeiras - sobretudo São Paulo - pode-se falar num verdadeiro processo de "financeirização do território", já que as variáveis financeiras (créditos, depósitos, seguros, investimentos, e a própria moeda, em suas diferentes formas), acabam por invadir mesmo os mais recônditos cantos do espaço nacional. Segundo a definição dos autores,

novos instrumentos financeiros são incorporados ao território na forma de depósitos e de créditos ao consumo. A sociedade, assim, é chamada a consumir produtos financeiros, como poupanças de diversas espécies e mercadorias adquiridas como dinheiro antecipado. Com isso o sistema financeiro ganha duas vezes, pois dispõe de um dinheiro social nos bancos e lucra emprestando, como próprio, esse dinheiro social para o consumo. Eis um dos caminhos da financeirização da sociedade e do território. É um movimento de concentração e dispersão (SANTOS \& SILVEIRA, 2001, p. 195).

Outros textos centrais que inauguram o campo dos estudos das finanças na geografia brasileira são de autoria de Leila Dias, com destaque para alguns de seus artigos (DIAS, 1989; 1992; 1996; 2009; DIAS e LENZI, 2009) e seu livro Réseaux d'information et réseau urbain au Brésil (1995). ${ }^{21}$ Neste livro, Dias nos mostra a íntima relação das redes bancárias com outras duas principais redes contemporâneas: as redes urbanas e as redes de telecomunicações. Conforme fica claro também em seu texto mais recente, a integração do mercado nacional através das rodovias e dos sistemas de telecomunicações permitiu a difusão dos bancos brasileiros, que se tornaram efetivamente nacionais a partir das décadas de 1960 e 70 . Outra variável central para a análise da

\footnotetext{
${ }^{21}$ Cabe destacar também que Dias coordenou em 2009 um dossiê especial dos Cadernos CRH (Vol. 22, 2009), intitulado "Finanças, política e território", que reúne diversos especialistas e pesquisadores do tema. Em texto que abre este Dossiê, a autora mostra que se buscava "avançar na compreensão do processo de financeirização contemporâneo, através do estudo de seus nexos, de seus atores e de suas implicações na dinâmica política e territorial, em múltiplas escalas geográficas" (DIAS, 2009, p. 11).
} 
organização do território são as "informações", que se consolidam como um dado fundamental da vida das corporações privadas (sobretudo as de grande dimensão), incluindo aí os bancos comerciais. Baseada também em algumas propostas de Milton Santos sobre o tema, a autora mostra que assistimos na década de 1970 "ao evento de uma nova etapa no processo de integração territorial, no curso da qual o poder de controle sobre a economia e o espaço vai cada vez mais repousar sobre a aptidão de alguns lugares de manipular a informação" (DIAS, 1995, p. 146).

A possibilidade de uso destas novas redes-suporte telemáticas permite que os bancos se tornem poderosos conglomerados, diversificando seus ativos e as empresas sob seu controle (intensificando sua ação também em atividades econômicas não-financeiras). Tendo como "estudo de caso" o Banco Bradesco, Dias (1992; 1995) mostra que esta instituição surge como um pequeno banco regional, e que paulatinamente vai se constituir no maior banco comercial nacional, acompanhando a própria difusão deste "meio técnico-científico informacional" que se estende no território a partir de meados da década de 1960. A reorganização interna do banco a partir da incorporação de novos sistemas informacionais (data-centers, equipamentos de informática, grandes computadores, caixas eletrônicos etc.) acelera a capacidade da empresa de transmitir e processar informações, e permite que uma eficiente divisão territorial do trabalho "interna" à firma se instale (com controle centralizado a partir da sede do banco situada na cidade de Osasco, SP).

No artigo "Porque os bancos são o melhor negócio no país? Hegemonia financeira e geografia das redes bancárias", a autora faz uma interpretação ainda mais abrangente da evolução do sistema bancário e financeiro nacional a partir de meados da década de 1950. Segundo Dias (2006), as novas tecnologias digitais fazem multiplicar os canais de comunicação dos bancos com seus clientes, além de permitir a criação de diferentes tipos de produtos financeiros à disposição dos consumidores e clientes. Como mostra a autora, "dinheiro virtual, cartões magnéticos inteligentes, home banking e transferência eletrônica de fundos rematerializam o dinheiro, que se transforma em unidades de informação transmitidas pelas redes de telecomunicações" (DIAS, 2006, p. 42). ${ }^{22}$

Das produções mais "recentes" sobre o tema no Brasil, vale mencionar um conjunto de artigos que tratam das finanças, mas sem a preocupação de trabalhar sistematicamente sua espacialidade. É o caso dos artigos de Lia Osório Machado (1996), Hindenburgo Pires (1997), Arroyo (2006) e Silveira (2009). Há também um conjunto de teses e dissertações que foram defendidas em universidades públicas, que tem aumentado a profundidade das discussões sobre o sistema financeiro e bancário brasileiro. ${ }^{23}$ Por fim, cabe destacar os trabalhos de Sandra Videira e Fabio

\footnotetext{
${ }^{22}$ São muito importantes também as considerações da autora em relação à evolução das normas que regem o sistema financeiro brasileiro, em especial a chamada Lei da Reforma Financeira (Lei no. 4.595 de 31/12/1964) e a Resolução no. 1.524 do Banco Central de 1988 (a chamada "mini-reforma" bancária). Ambas influenciaram diretamente a conglomeração dos bancos brasileiros.

${ }^{23}$ Foram identificadas 15 teses e dissertações que trataram mais diretamente do tema deste artigo: 1. TAVARES, C.V.M. Padrões de localização dos bancos privados no Brasil. Rio de Janeiro: Instituto de Geociências/UFRJ, 1996. 2. CONTEL, F.B. Finanças municipais e território. Horizontalidades e verticalidades no município de Bauru (SP). (Dissertação de mestrado). São Paulo: Faculdade de Filosofia, Letras e Ciências Humanas/USP, 2001. 3. GOMES, M.F. A territorialidade do Bradesco: de pequeno banco caipira a maior banco privado de varejo. (Dissertação de mestrado). São Paulo: Faculdade de Filosofia, Letras e Ciências Humanas/USP, 2001. 4. SILVA Jr., G.O. BNDES: importante ordenador do território brasileiro. (Dissertação de mestrado). Niterói: Instituto de Geociências/UFF, 2004.5. GOMES, M.F. A territorialidade dos conglomerados financeiros no Brasil. (Tese de doutorado). São Paulo: Faculdade de Filosofia, Letras e Ciências Humanas/USP, 2006. 6. FARIAS, H.C. O BNDES e as privatizações no uso do território brasileiro. (Dissertação de mestrado). Instituto de Geociências/UNICAMP, 2008. 7. SOUZA, A.B. A territoria-
} 
Contel, que estudaram alguns aspectos importantes da relação entre o espaço geográfico e as finanças. Videira publica em 2009 o livro Globalização financeira: um olhar geográfico sobre a rede dos bancos estrangeiros no Brasil $^{24}$, em que estuda a internacionalização bancária no território brasileiro, com destaque para a compra do banco Banespa (até então sob controle do governo do estado de São Paulo) pelo banco espanhol Santander. Contel, por sua vez, publicou em 2009 e 2011 dois trabalhos sobre estes temas: tratam-se do artigo "Espaço geográfico, sistema bancário e a hipercapilaridade do crédito no Brasil" (2009) e do livro Território e Finanças. Técnicas, normas e topologias bancárias no Brasil (2011). ${ }^{25}$ Segundo o autor, é possível analisar o desenvolvimento do sistema financeiro brasileiro através do estudo da topologia dos bancos comerciais, e de sua enorme capilarização recente. Com a expansão de um meio técnico ainda mais intensivo em técnicas da informação, estes bancos puderam otimizar seus sistemas de prestação de serviços e de criação de novos produtos financeiros, o que acabou por difundir o crédito por praticamente todo o território brasileiro (incluindo aí um robusto processo de endividamento da população de mais baixa renda, mesmo em cidades de dimensão média e pequena) (CONTEL, 2011).

\section{Considerações finais}

Passados pouco mais de 60 anos da publicação do livro precursor de Jean Labasse (1955), é possível dizer que muito se avançou no estudo da relação das finanças com o espaço geográfico. A começar pela própria evolução das escalas de análise com que se estudam as finanças, no início e no final da trajetória aqui descrita: de abordagens restritas as realidades locais e regionais da ação dos bancos, a geografia passou a se preocupar com o alcance nacional e global de todos os tipos de atores financeiros, permitindo ganhos explicativos em relação entendimento do capitalismo atual, um capitalismo mundializado e "dirigido pelas finanças" (GUTTMANN, 2008).

lidade do Banco do Brasil na 'era das telecomunicações'. (Dissertação de mestrado). São Paulo: Faculdade de Filosofia, Letras e Ciências Humanas/USP. 2008. 8. VIEIRA, C.E. Rede bancária e rede de cidades. O processo de reestruturação ocorrido no período de 1970 a 2006. (Dissertação de mestrado). Maringá: Universidade Estadual de Maringá, 2009. 9. CORNETTA, A. A financeirização do clima: Uma abordagem geográfica do mercado de carbono e suas escalas de operação. (Dissertação de mestrado). São Paulo: Faculdade de Filosofia, Letras e Ciências Humanas/USP, 2010. 10. SCHERMA, R.A. Capitalismo financeiro e uso corporativo do espaço da nação: o território como recurso. (Tese de doutorado). Rio Claro: Universidade Estadual Paulista, Instituto de Geociências e Ciências Exatas, 2012. 11. MEDEIROS, D.A. Financeirização do território e circuitos da economia urbana: agentes de crédito, técnicas e normas bancárias. Um exemplo em Alagoas. (Dissertação de mestrado). São Paulo: Faculdade de Filosofia, Letras e Ciências Humanas/USP, 2013. 12. DE PAULA, C.G. Do território ao lugar: bancos comunitários, moedas locais e o circuito inferior da economia urbana em São Paulo-SP. (Dissertação de mestrado). São Paulo: Faculdade de Filosofia, Letras e Ciências Humanas/USP, 2014. 13. POLEZI, C. O BNDES e o financiamento da integração sul-americana: sistemas de engenharia na fronteira Brasil-Guiana Francesa. (Dissertação de mestrado). São Paulo: Faculdade de Filosofia, Letras e Ciências Humanas/USP. 2014. 14. ALVES, C.Z.J. A topologia dos bancos de investimento no Brasil: primazia urbana e formação do complexo corporativo metropolitano de São Paulo. (Dissertação de mestrado). São Paulo: Faculdade de Filosofia, Letras e Ciências Humanas/USP, 2015. 15. RIBEIRO, C.C. A relação entre expansão territorial do crédito bancário e desigualdade econômica inter-regional no Brasil contemporâneo (2000-2010). (Tese de doutorado). São Paulo: Faculdade de Filosofia, Letras e Ciências Humanas/USP, 2015.

${ }^{24}$ Este trabalho foi originalmente apresentado como tese de doutorado de Videira, defendida em 2006 na Unesp de Presidente Prudente (SP).

${ }^{25}$ Este trabalho foi originalmente apresentado como tese de doutorado, defendida em 2006 na Universidade de São Paulo. 
Outra constatação que pode ser feita é em relação à sensível influência da geografia francesa em alguns dos principais artigos escritos no Brasil sobre a relação finanças/geografia. Esta influência fica explícita nos textos de Coracy Amazonas (1965) e Maria Rita Guimarães (1967), mas também pode ser identificada nos escritos de Helena Kohn Cordeiro e de Roberto Lobato Correa. Por mais que estes dois últimos também fossem leitores de geógrafos e economistas norte-americanos, fica evidente o recurso deles aos conceitos de rede urbana e de "equipamento terciário superior" (LABASSE, 1976) para o entendimento da organização territorial das finanças no Brasil, por exemplo. Ambos, aliás, citam textualmente os livros de Jean Labasse em todas as obras consultadas para a redação deste artigo.

As maiores novidades da geografia brasileira para a interpretação do fenômeno financeiro na atualidade parecem ser aquelas propostas pelo geógrafo Milton Santos, conforme visto na segunda parte do texto. Como mostra Santos, ainda que seja possível falar em uma "tirania das finanças" - e que elas tenham ganhado uma autonomia significativa no período da globalização -, as finanças seguem dependendo de uma série de fatores que são eminentemente geográficos, como é o caso das próprias normas e leis dos países - os "conteúdos normativos do espaço" assim como de todas as infraestruturas, sistemas e objetos técnicos que permitem este funcionamento quase ubíquo e instantâneo das corporações financeiras. Há, portanto, uma causalidade que deriva dos elementos que compõem o espaço geográfico, e tornar explícita esta causalidade talvez seja uma tarefa precípua da geografia contemporânea.

Por fim, cabe ressaltar que as contribuições dadas pelos geógrafos mencionados neste artigo permitiram também um enriquecimento da epistemologia geográfica. Nesta trajetória da explicação geográfica do fenômeno financeiro, alguns conceitos foram abandonados, outros foram ressignificados, e temas e termos novos surgiram, trazendo para a geografia uma maior capacidade de crítica e de interpretação do atual período histórico (como pôde ser destacado para o caso brasileiro). Como assevera Martin (1996, p. 56), "precisamos de novos conceitos e teorias para que as novas realidades façam sentido". Conforme visto, conceitos bastante tradicionais como os de "meio", "rede", "região", ao serem re-significados com os problemas e debates concretos do tempo presente, podem se tornar instrumentos úteis para o entendimento da espacialidade contemporânea das finanças. 
ALBERS, M.B. Financial geography: introduction to the Virtual Issue. Transactions of the Institute of British Geographers v.40, n.2, p. 300-305, 2015.

AMAZONAS, C. Organização bancária. In: BERNARDES, L. (Ed.). O Rio de Janeiro e sua região. Rio de Janeiro: CNG/IBGE, 1965, p. 109-111.

ANDRADE, M.C. Geografia, ciência da sociedade: uma introdução à análise do pensamento geográfico. São Paulo: Atlas, 1987.

ARROYO, M. A vulnerabilidade dos territórios nacionais latinoamericanos: o papel das finanças. In: LEMOS, A.I.; SILVEIRA, M.L.; ARROYO, M. (Org.). Questões territoriais na América Latina. São Paulo/Buenos Aires: Universidade de São Paulo/CLACSO, 2006, p. 77-190.

AZEVEDO, O.B. O Comércio carioca: sua função regional e sua posição no âmbito nacional. A rede bancária. In: AGB/CNG, Aspectos da Geografia Carioca. Rio de Janeiro: CNG/IBGE, 1962, p. 125-150.

BERNARDES, L. (Ed.). O Rio de Janeiro e sua região. Rio de Janeiro: CNG/IBGE, 1965.

BONNET, J. Jean Labasse. Géocarrefour v.77, n.2, p. 215, 2002.

CONTEL, F.B. Espaço geográfico, sistema bancário e a hipercapilaridade do crédito no Brasil. Caderno CRH v.22, n.55, p. 119-134, 2009.

Território e finanças. Técnicas, normas e topologias bancárias no Brasil. São Paulo: Annablume, 2011.

CORDEIRO, H.K. Os principais pontos de controle da economia transnacional no espaço brasileiro. Boletim de Geografia Teorética v.16/17, n.31/34, p. 153-196, 1986-87.

. A circulação da informação no espaço brasileiro e o sistema bancário. Geografia (Rio Claro) v.16, n.1, p. 23-36, 1991.

. A 'cidade mundial' de São Paulo e o complexo corporativo do seu centro metropolitano. In SANTOS et alli (Org.). Fim de Século e Globalização. O Novo Mapa do Mundo. São Paulo: Hucitec/ANPUR, 1993, p. 318-331.

CORRÊA, R.L. Concentração bancária e os centros de gestão do território. In: Estudos sobre a rede urbana. Rio de Janeiro: Bertrand Brasil, 2006.

. Dinâmica do Espaço Financeiro. In: SCARLATTO, F.C.; SANTOS, M; SOUZA, M.A.A.; ARROYO, M. (Org.). O Novo Mapa do Mundo. Globalização e Espaço LatinoAmericano. São Paulo: HUCITEC-ANPUR, 1993, p. 163-168.

DIAS, L.C. Un indicateur de l'organisation territoriale: l'activité bancaire et son évolution au Brésil. In: BENKO, G. La dynamique spatiale de l'économie contemporaine. Paris: Éditions de I'Espace Européen, 1989, p. 293-308.

. O sistema financeiro: aceleração dos ritmos econômicos e integração territorial. Anuário do Instituto de Geociências (UFRJ) v.15, p. 43-53, 1992.

. Réseaux d'information et réseau urbain au Brésil. Paris: L'Harmattan. 1995.

. Redes eletrônicas e novas dinâmicas do território brasileiro. In CASTRO, I.E., GOMÊS, P.C.C., CORREAA, R.L. (Org.), Brasil. Questões atuais da organização do território. Rio 
de Janeiro: Bertrand Brasil, 1996, p. 115-144.

Porque os bancos são o melhor negócio no país? Hegemonia financeira e geografia das redes bancárias. In: SILVESTRE, E. (Org.), Que país é esse? Pensando o Brasil contemporâneo. São Paulo: Ed. Globo, 2006, p. 27-62.

DIAS, L.C.; LENZI, M.H. Reorganização espacial de redes bancárias no Brasil: processos adaptativos e inovadores. Caderno CRH v.22, n.55, p. 97-117, 2009.

DRESCH, J. Déclin du colonialisme. La Pensée v.4, p. 95-100, 1946.

. Reflexões sobre a geografia. In: GUSMÃO PINTO, J.M. (Ed.). Reflexões sobre a geografia. São Paulo: AGB/SP, 1980[1948], p. 5-26.

GASPARINI, I. Áreas geográficas do dinheiro. Revista da Sociedade de Geografia do Rio de Janeiro v.XXXIV, p. 63-65, 1929.

GOTTMANN, J. Les Marchés de matières premières. Paris: Armand Colin, 1947.

. Megalopolis. The urbanized northeastern seabord of the United Sates. New York: The Twentieth Century Fund, 1961.

GRAVIER, J-F. Paris et le désert français. Paris: Flammarion, 1947.

GUIMARÃES, M.R.S. A função financeira. In: DUARTE, A.C. (Ed.). A área central da cidade do Rio de Janeiro. Rio de Janeiro: CNG/IBGE, 1967, p. 97-101.

GUTTMANN, R. Uma introdução ao capitalismo dirigido pelas finanças. Novos Estudos Cebrap v.82, p. 11-33, 2008.

LABASSE, J. Les Capitaux et la Région. Étude Géographique. Essay sur le commerce et la circulation des capitaux dans la région lyonaise. Étude Géographique. Paris: Presses de la Fondation Nationale de Sciences Politiques, 1955.

L'espace financier. Paris: Armand Colin, 1974.

LEYSHON, A. Geographies of money and finance I. Progress in Human Geography v.19, n.4, p. 531-543, 1995.

. Geographies of money and finance II. Progress in Human Geography v.21, n.3, p. 381-392, 1997.

MACHADO, L.O. O comércio ilícito de drogas e a geografia da integração financeira. In: CASTRO, I.E., GOMES, P.C.C.; CORRÊA, R.L. (Org.). Brasil. Questões atuais da organização do território. Rio de Janeiro: Bertrand Brasil, 1996, p. 15-64.

MARTIN, R. The new economic geography of money. In: MARTIN, Ron (Ed.), Money and the space economy. New York: Wiley \& Sons, 1999, p. 3-27.

Teoria econômica e geografia humana. In: GREGORY, D.; MARTIN, R.; SMITH, G. $(E d$.$) , Geografia humana. Sociedade, espaço e ciência social. Rio de Janeiro: Jorge Za-$ har Editor, 1996, p. 31-64.

MONBEIG, P. Capital e geografia. In: São Paulo: DIFEL, 1957, p. 215-236.

Novos estudos de geografia humana brasileira.

Pioneiros e fazendeiros no estado de São Paulo. São Paulo: Hucitec/Polis, 1984[1952].

PEGAIA, U.A. A Rede bancária da cidade de São Paulo. Dissertação de mestrado. São Paulo: 
Faculdade de Filosofia, Letras e Ciências Humanas, 1965. 220p.

PIRES, H. Reestruturação inovativa e reorganização das instituições financeiras no setor privado no Brasil. GEOUerj v.2, p. 65-79, 1997.

ROCHEFORT, M. L'organisation urbaine de l'Alsace. Paris: Editions Ophyrs, 1960.

SANTOS, M. Técnica, espaço, tempo. Globalização e meio técnico-científico informacional. São Paulo: Hucitec, 1994. 1996.

A Natureza do espaço. Técnica e tempo, razão e emoção. São Paulo: Hucitec, . O dinheiro e o território. GEOgraphia v.1, n.1, p. 1-13, 1999.

. Por uma outra globalização. Do pensamento único à consciência universal. Rio de Janeiro: Record, 2000.

SANTOS, M.; SILVEIRA, M.L. O Brasil. Território e sociedade no início do século XXI. Rio de Janeiro: Record, 2001.

SILVA, C.A.F. A espacialidade da concentração bancária. Boletim Goiano de Geografia v.14, n.1, p. 1-21, 1994.

Transformações da rede de gestão territorial do Banco Nacional S/A sob a égide da revolução telemática. Território v.6, p. 55-71, 1999.

SILVA, J.B. França e a escola brasileira de geografia: verso e reverso. Fortaleza: Edições UFC, 2012.

SILVEIRA, M.L. Finanças, consumo e circuitos da economia urbana na cidade de São Paulo. Caderno CRH v.22, n.55, p. 65-76, 2009.

SOKOL, M. Towards a 'newer' economic geography? Injecting finance and financialisation into economic geographies. Cambridge Journal of Regions, Economy and Society v.2, p. 501-515, 2009. 